Original Article

\title{
SCHEDULED AND STANDARDISED TRAINING IMPROVED EMPLOYEES' KNOWLEDGE ON GOOD MANUFACTURING PRACTICES (GMP)
}

\author{
G. K. S. SINGH' ${ }^{1}$, K. A. KU AZMAN ${ }^{2}$, M. A. ABDUL HADI ${ }^{3}$, Z. JAAFAR ${ }^{3}$, M. M. R. MEOR MOHD AFFANDI2*
}

${ }^{1}$ Department of Pharmaceutical Life Sciences, Faculty of Pharmacy, Universiti Teknologi MARA (UiTM), 42300 Bandar Puncak Alam, Selangor, Malaysia, 2Department of Pharmaceutics, Faculty of Pharmacy, Universiti Teknologi MARA (UiTM), 42300 Bandar Puncak Alam, Selangor, Malaysia, ${ }^{3}$ Che Mah and Sons Sdn. Bhd. Lot 2959, Kg Simpang Empat, Chetok, 17000, Pasir Mas, Kelantan Email: meor@salam.uitm.edu.my

Received: 19 Jun 2017 Revised and Accepted: 30 Nov 2017

\section{ABSTRACT}

Objective: The present study aimed to evaluate the effectiveness of good manufacturing practices (GMP) training in enhancing the awareness of employees from a selected traditional medicine industry towards GMP principles.

Methods: This study has employed two methodologies which are the ethnographic and descriptive method. The ethnographic method employed observations and photographs to record the factory facility and documentation system prior and after GMP training. A descriptive method employed data collection through five main sections questionnaire prior and after the completion of GMP training. The data were analysed using statistical package for social sciences (SPSS) version 23.0.

Results: The findings from this study revealed that major facility and documentation improvisation were made after training was conducted which were installation of centralized air conditioner and systematic standard operation procedure (SOP) documentation. Results from the questionnaire conducted on GMP revealed significant value with $\mathrm{p}<0.05$. Employees showed average increased percentage of knowledge in all five sections questionnaire which were personnel practices (11\%), premise and equipment (12\%), documentation (9\%), production (4\%) and product's quality control $(11 \%)$.

Conclusion: As a conclusion, we reported that GMP training is crucial to strengthen the employees' knowledge on GMP as to improve products manufacturing quality. Regular training (once a y) keeps the employees updated.

Keywords: Good manufacturing practices, GMP training, Scheduled training, Traditional medicine

(C) 2018 The Authors. Published by Innovare Academic Sciences Pvt Ltd. This is an open access article under the CC BY license (http://creativecommons.org/licenses/by/4.0/) DOI: http://dx.doi.org/10.22159/ijpps.2018v10i1.20827

\section{INTRODUCTION}

Good manufacturing practices (GMP) also well known by Malaysian as "Amalan Perkilangan Baik" is a worldwide recognized guideline set forth by the World Health Organization (WHO) which focuses on the management control of manufacturing and quality control of food, pharmaceutical products and medical devices. GMP can be defined as procedures employment for a drug product or substance manufacturing that meets the claimed requirements for purity, identity, safety and quality under a quality management system [1]. Pharmaceutical, cosmetic, health supplement and traditional medicine companies in Malaysia are bound to GMP guidelines for their licensing. The guideline was first implemented in 1984 for Malaysian pharmaceutical industries and the implementation was further extended to traditional medicine and health supplement industries in 2007 and 2009, respectively. Through this implementation, manufacturers have been systematically inspected by relevant enforcement agency to ensure they meet the GMP requirements [2].

WHO defined traditional medicine as the sum total of the knowledge, skills and practices based on the theories, beliefs and experiences of the indigenous from different cultures, whether explicable or not, used in the maintenance of health, as well as in the prevention, diagnosis, improvement or treatment of physical and mental illnesses [3]. Traditional medicine also known as complementary medicine is a part of the ancient practice to improve health and wellbeing of people in the practiced country throughout the world [4] by handed down indigenous cultures from generation to generation [5]. Currently, traditional and complementary medicine are widely used in various health supplement and herbal products [6] to provide many essential biological functions [7] and as an alternative treatment of wide range of vital disease [8]. In Malaysia it is mostly manufactured by small companies registered as small and medium enterprises (SMEs). The SMEs play a big role in Malaysia's economic growth as they supported the big industries and providing job opportunities to the locals [9]. Basically, most SMEs are focused on supplying products to local market and not globally. However, the demand for traditional medicine products in Malaysia have tremendously increased [10] with estimated income of US $\$ 93$ billion in 2015 and this value is expected to increase [11]. This was the driving force for SMEs manufacturers to increase their productivity and quality in order to survive and move forward [12].

The SMEs in Malaysia are under competitive pressure and urgency to improve their performance level [9]. The consumers' preference towards alternative medicine has been the driving force to the Malaysian traditional medicinal companies to improve their product quality according to international standards that require the implementation of GMP guidelines. SMEs manufacturers in developing country such as Malaysia are confronting difficulty in meeting GMP requirements as it requires high investment in the facility and human capital development [13]. The practice of GMP by the employees in SMEs' traditional medicines manufacturing sector should become the first priority to the manufacturers as it is the preliminary step for a safe production of a high quality products. The employees should be sufficiently trained and strictly adhere to the GMP guidelines while working. Decision to provide GMP training by the higher management is essential as it has become a solution for this matter. In fact, regular training can strengthen employees' knowledge as well as being updated with the current GMP practice [2]. Paul et al. (2014) concluded GMP guidelines as one of the main constraints before technology implementation [14]. Knowing that lacking in technologies, large scale cultivation activities and skilled manpower, most SMEs could venture into government authorized GMP practice to expand their potential in the business [15]. 
As a whole, it is advised that at least one qualified GMP trainer or institution should be appointed to provide scheduled training, information and to supervise the selected manufacturer. Hence, this study was performed with the aim to provide more information on how GMP training conducted for a selected traditional medicinal company is a reliable approach to increase awareness among employees practicing GMP. This is a pilot study adopted the ethnographic and cross-sectional descriptive method studied on the effectiveness of scheduled and standardised training programme aiming to increase efficiency and knowledge of workforce on GMP.

\section{MATERIALS AND METHODS}

\section{Methods}

\section{Study design}

This study has employed two methodologies which are the ethnographic and descriptive method. The ethnographic method can be defined as the systematic study of people and culture and description of people's way of life or work system. The researcher's observation is to provide a detailed recording of everyday life and practice. In this study, we applied two major ethnographic studies, namely observations and photographs. The observations and photographs were made to record the factory facility and documentation system prior and after consultation.

The descriptive method has adopted a cross-sectional questionnaire-based survey through data collection from the population. The structured questionnaire was designed according to the standard GMP guidelines. It is divided into five sections 1) personnel practices 2) premise and equipment 3) documentation 4) production and 5) product's quality control. The questionnaire was distributed to the employees of the selected SME's company as the key respondents. The assessment on workers' awareness on GMP was evaluated based on a five-point Likert Scale. The respondents were asked to rank from a scale 1-corresponding to highly agree to 5-as highly disagree.

\section{Sample selection}

Employees [ $n=39$, age $44 \pm 10.3$ y (SD)] were selected and evaluated for their knowledge on GMP before and after two days of scheduled GMP training program. Their academic qualification ranged between primary standard five and undergraduate degree holders. Twenty of the employees have working experience of more than $10 \mathrm{y}$ and the remaining less than $10 \mathrm{y}$. The training has involved the participation of company's higher authority and discussion with GMP trainer to improve the factory condition to meet the GMP requirements.

\section{Data collection}

The obtained data are presented in the form of photographs and graphs. At the end of the GMP training program, two sets of evaluation forms completed by the employees were collected, tabulated and grafted using Microsoft Excel 10.0. Data are expressed in cumulative percentage of agree and disagree as the respondents' responses before undertaking the GMP training were compared with after training. The data were analysed using statistical package for social sciences (SPSS ${ }^{\circledR}$ ), version 23.0. The data was analysed by using $2 \times 2$ tables, chi-square or Fisher exact test statistics with a probability of significant $P<0.05$.

\section{RESULTS}

\section{Graduate training on GMP training curriculum}

A skillful and experienced trainer with complete knowledge on the subject was appointed to design a training course for the employees. In this study, we selected and trained a graduate intern as a GMP trainer to ensure continuous GMP assessment in the selected company with supervision from an experienced trainer. The graduate intern was selected from a strict interview session by the academicians from Universiti Teknologi MARA (UiTM). The graduate intern was intensively trained on the theoretical and practical training on GMP by an experienced academician with $13 \mathrm{y}$ of experience in the industry. It was a period of knowledge transfer from the experienced trainer to the graduate intern. During the intensive eight months, various critical aspects on GMP such as SOP training, employees' on the job training and GMP training curriculum was covered.

In mid-2014, the graduate intern was sent to the selected SME's company for theoretical and practical training on company quality system and production operations. Details on how the employees perform their tasks and how the management implement GMP to their workers has been used as a benchmark to developed a proper GMP training curriculum. With the advised and monitoring from the experienced academician, the graduate intern has developed a GMP training programme and the company's documentation system was upgraded as per GMP requirements (December 2014-November 2015).

Through a series of upgrading theoretical and practical training on GMP principles and company's documentation system to the staff and employees in that period, a GMP's training was conducted at the end of the year 2015 to study the effectiveness of GMP training and facility improvement.

\section{Major facility improvisation}

There were two majors improvisation made by the company after the training which was the ventilation system and documentation. Before the training was done, the company used a separated air conditioner in the building (fig. 1: A). The split units of the horizontal air conditioner can easily collect dust on the surface and constant cleaning is essential. During the cleaning process, dust may be distributed throughout the area and can affect the products' hygiene. After the training, a centralized air conditioner was installed (fig. 1: B). The system connects to all process and production area vertically through the ceiling while its compressor and air filter are placed outside the building.

The documentation system has been upgraded by the company by establishing GMP's training manual and improvisation of standard operating procedure (SOP). The developed SOP is easy to understand, precise and more detail (fig. 1: D) compared to previous SOP (fig. 1: C).

\section{Employees' GMP training assessment}

The data presented is mainly based on the questionnaires distributed to the respective 39 employees were assessed before and after GMP training. Several questions from each section were selected and grafted to evaluate the employees' awareness on GMP.

\section{Section1: key personnel perception on GMP training}

Seven selected questions from Section 1 of the questionnaire were tabulated (table 1: Key personnel). Employees were able to understand the importance of procedure understanding before work (frequency of $84.2 \%$ vs $94.6 \%$ ). They are aware of equipment cleanliness prior to production with the percentage of before and after training were $85.5 \%$ and $91.4 \%$, respectively. There was a significant increase in conscience levels of employees to attend GMP training $(77.8 \%$ vs $97.3 \% ; P=0.014)$. The employees disagreed that the GMP training should be conducted for managerial staff only ( $80 \%$ vs $91.9 \%$ ), indicating their capability of understanding the importance and benefits of attending regular GMP training. After GMP training was conducted, approximately 93.5\% employees agreed that they have basic knowledge on GMP compared to $80.6 \%$ before training. Most of the employees agreed that they should use protective wear before entering production site and possess good hygiene working attitude $(97.2 \%$ vs $100 \%$ and $91.7 \%$ vs $94.6 \%$, respectively). Section 2: premise and equipment

This section assessed the knowledge of the employees on the facility and equipment requirements. Of the total respondent, the majority agreed that the premise should be equipped with proper drainage system and good air ventilation, ( $97.4 \%$ vs $100 \%)$. The evaluation is insignificant for question two $(9.1 \%$ vs $8.1 \% ; P=1.000)$ as they are knowledgeable about the importance of not conducting two different processes in a same room. The employees agreed that they were able to carry out specific prevention action at high-risk contamination site $(83.3 \%$ vs $91.7 \%)$. For both question four and five, the employees agreed that their quality control laboratory has 
enough space for sample storage and they are capable to handle and take good care of the production equipment $(87.2 \%$ vs $100 \%$ and $94.6 \%$ vs $100 \%$, respectively). The frequency of employees that agreed the indoor and the outdoor equipment should be separated was higher after the GMP training compared to before training (50\% vs $77.8 \% ; P=0.018$ ) (table 1: Premise and equipment).

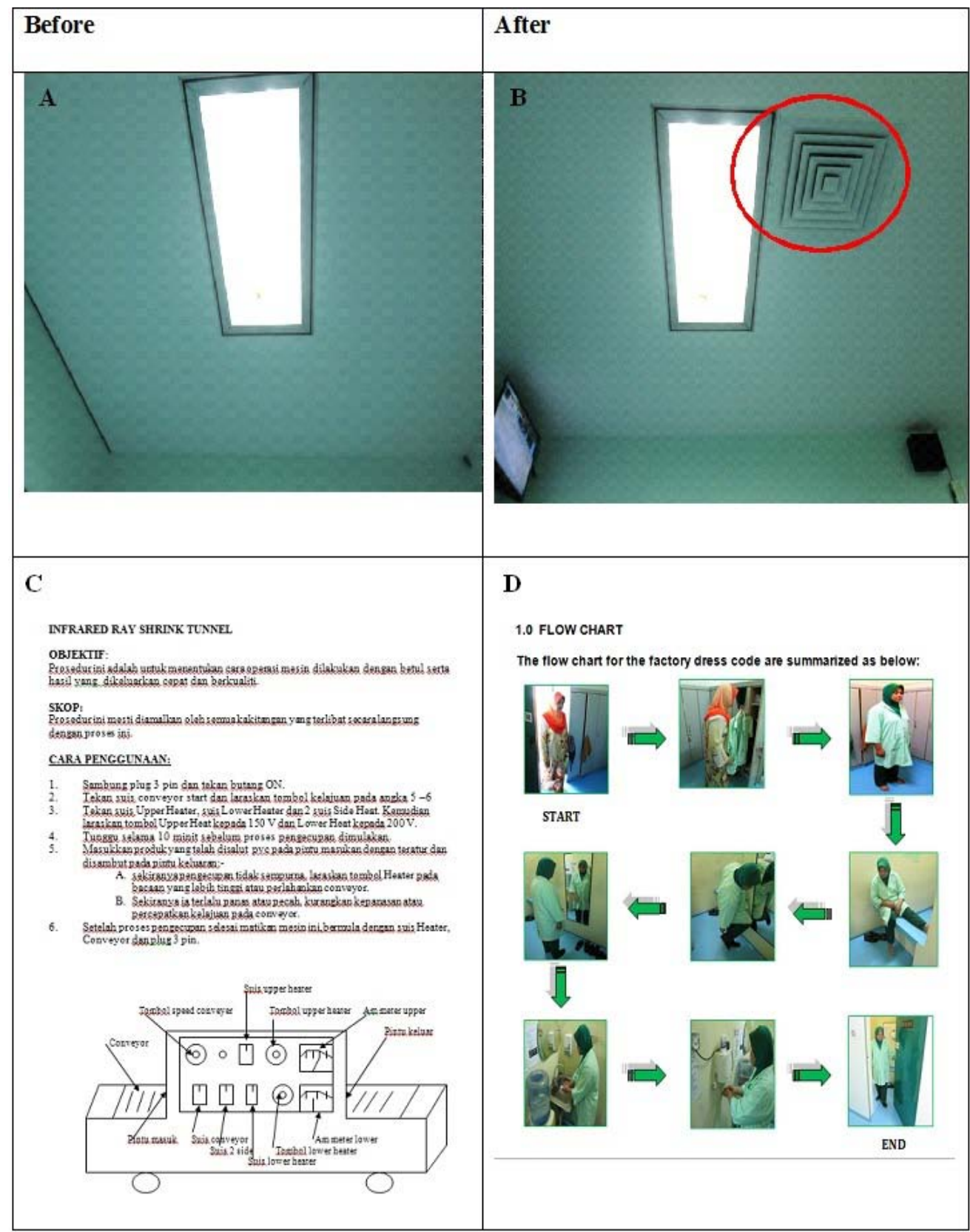

Fig. 1: The centralized air conditioner in the factory and standardised and systematic SOP documentation before (A and C) and after (B and D) GMP consultation

\section{Section 3: documentation}

The third section evaluated the ability of the employees to perform proper documentation for tracking purposes and future reference. The result shows a minimal increase of percentage in questions one, two, three, four and five after GMP training (table 1: Documentation). The employees reported insignificant result for questions one $(97.3 \%$ vs $100 \%$; $P=1.000)$, two $(87.2 \%$ vs $97.3 \%$; $P$ $=0.201$ ), four ( $97.1 \%$ vs $94.4 \% ; P=1.000)$ and five $(97.4 \%$ vs $100 \%$; $\mathrm{P}=1.000$ ). It is well informed that the employees are knowledgeable in this specific area. Other questions three and six showed a significant difference. Univariate analysis showed that the employees understood that having clear, accurate and updated documents or records are very important for tracking purposes (87.2\% vs $100 \% ; P=0.024)$. Employees reported significantly increase in awareness that corrections on documents using correction tape is prohibited $(68.2 \%$ vs $91.7 \% ; P=0.032)$. It is a concern that most of the employees are unaware before the GMP training that using a correction tape is prohibited when changes are being made on documents or records in order to assure their validity.

\section{Section 4: production}

From the result shown (table 1: Production) most of the questioned area assessed is well understood by the employees. They are capable to handle raw materials and products as written in the standard operation procedures ( $97.4 \%$ vs $97.3 \%)$, competent to inspect raw materials received for confirmatory purposes $(92.3 \%$ vs $100 \%)$, know the importance of labelling raw materials $(88.6 \%$ vs $89.2 \%)$, 
using only approved raw materials by quality control department $(94.7 \%$ vs $97.3 \%)$ and regularity of assuring packaging container cleanliness (97.4\% vs $100 \%)$. Meanwhile, positive attitude of being responsible to report any abnormality found on materials to the quality control department has increased from $94.9 \%$ to $100 \%$. After training, $86.5 \%$ employees agreed that production of different products should be separated in a different room compared to prior training $(74.3 \%)$.

\section{Section 5: quality control}

The data on products quality control can be seen from the result shown (table 1: quality control). Question one and two showed a slight increase in percentage where the employees agreed that they have a proper quality control system to acquire certain standards and have proper storage of original records and laboratory log book for future access $(97.4 \%$ vs $100 \%$ and $94.4 \%$ vs $97.2 \%$, respectively). The employees agreed that they should use outside laboratory service if the factory does not have one ( $87.1 \%$ vs $94.4 \%)$. The employees significantly agreed that the end products' quality is the manufacturer's responsibility ( $71 \%$ vs $91.9 \% ; P=0.030$ ).

An increase of $14.4 \%$ in question five showed that the employees understood that employees from production department are restricted to enter the quality control department $(66.7 \%$ vs $81.1 \%)$. Whereas, $84.4 \%$ (after training) employees agreed that heavy metal test should be conducted on the final products manufactured compared to $75.9 \%$ (before training).

Table 1: Selected questionnaire from five main sections with comparison of knowledge percentage before and after GMP training statistically using Fisher's exact test

\begin{tabular}{|c|c|c|c|c|}
\hline \multirow[t]{2}{*}{ Section } & \multirow[t]{2}{*}{ Questionnaire } & \multicolumn{2}{|c|}{ Answers, an (\%) } & \multirow{2}{*}{$\begin{array}{l}\text { bfisher's exact test } \\
\text { P value }\end{array}$} \\
\hline & & Before & After & \\
\hline \multirow[t]{7}{*}{ Key personnel } & Importance of understanding procedure before work. & 84.2 & 94.6 & 0.262 \\
\hline & Equipment cleanliness should be checked before work. & 85.5 & 91.4 & 0.711 \\
\hline & Employees are required to attend GMP training programme. & 77.8 & 97.3 & $0.014^{*}$ \\
\hline & GMP training should be conducted for managerial staff only. & 20.0 & 8.1 & 0.183 \\
\hline & My knowledge on GMP is very good. & 80.6 & 93.5 & 0.255 \\
\hline & Employees should use protective wear before entering production site. & 97.2 & 100.0 & 1.000 \\
\hline & Possess good hygiene working attitude. & 91.7 & 94.6 & 0.674 \\
\hline \multirow[t]{6}{*}{$\begin{array}{l}\text { Premise and } \\
\text { equipment }\end{array}$} & $\begin{array}{l}\text { Necessity of premise equipped with proper drainage system and good } \\
\text { air ventilation. }\end{array}$ & 97.4 & 100.0 & 1.000 \\
\hline & Two different processes can be done in a same room. & 9.1 & 8.1 & 1.000 \\
\hline & $\begin{array}{l}\text { Employees were able to carry out specific prevention action at high risk } \\
\text { contamination site. }\end{array}$ & 83.3 & 91.7 & 0.452 \\
\hline & $\begin{array}{l}\text { Quality control laboratory has enough space to store samples for } \\
\text { analysis. }\end{array}$ & 87.2 & 100.0 & $0.050^{*}$ \\
\hline & $\begin{array}{l}\text { Production equipment shall be properly maintained and in compliance } \\
\text { with its use. }\end{array}$ & 94.6 & 100.0 & 0.493 \\
\hline & $\begin{array}{l}\text { Equipment used for the preparation of internal product must be } \\
\text { separated from the product for external use. }\end{array}$ & 50.0 & 77.8 & $0.022^{*}$ \\
\hline \multirow[t]{6}{*}{ Documentation } & $\begin{array}{l}\text { Documents or records must be approved and signed by the entrusted } \\
\text { personal. }\end{array}$ & 97.3 & 100.0 & 1.000 \\
\hline & $\begin{array}{l}\text { Have proper documentation for every batch products for products' } \\
\text { history identification. }\end{array}$ & 87.2 & 97.3 & 0.201 \\
\hline & Documents and records must be clear, precise and updated. & 87.2 & 100.0 & $0.050^{*}$ \\
\hline & The data storage system must be verified and backed-up. & 97.1 & 94.4 & 1.000 \\
\hline & Any changes to the documents and records should be signed and dated. & 97.4 & 100.0 & 1.000 \\
\hline & $\begin{array}{l}\text { The use of correction liquid is allowed if there are any changes to be } \\
\text { made to the document records. }\end{array}$ & 31.8 & 8.3 & $0.032 *$ \\
\hline \multirow[t]{7}{*}{ Production } & $\begin{array}{l}\text { Capable to handle raw materials and products as written in the standard } \\
\text { operation procedures. }\end{array}$ & 97.4 & 97.3 & 1.000 \\
\hline & $\begin{array}{l}\text { All raw materials received are checked to ensure only the ordered } \\
\text { materials are sent. }\end{array}$ & 92.3 & 100.0 & 0.241 \\
\hline & $\begin{array}{l}\text { Responsible to report any abnormality found on materials to the quality } \\
\text { control department. }\end{array}$ & 94.9 & 100.0 & 0.494 \\
\hline & Importance of labelling raw materials. & 88.6 & 89.2 & 1.000 \\
\hline & $\begin{array}{l}\text { Raw materials used for production must be approved by quality control } \\
\text { department. }\end{array}$ & 94.7 & 97.3 & 1.000 \\
\hline & $\begin{array}{l}\text { Production of different products should not be carried out } \\
\text { simultaneously in the same room. }\end{array}$ & 74.3 & 86.5 & 0.240 \\
\hline & Containers used for packaging is clean and free of any particles. & 97.4 & 100.0 & 1.000 \\
\hline \multirow[t]{6}{*}{ Quality control } & $\begin{array}{l}\text { Quality control system must be set-up to ensure that the manufactured } \\
\text { product met the standards set. }\end{array}$ & 97.4 & 100.0 & 1.000 \\
\hline & $\begin{array}{l}\text { All original data such as laboratory log books and records must be } \\
\text { appropriately kept and easily accessible. }\end{array}$ & 94.4 & 97.2 & 1.000 \\
\hline & $\begin{array}{l}\text { If the manufacturing plant does not have a laboratory, the management } \\
\text { may use services of external laboratories. }\end{array}$ & 87.1 & 94.4 & 0.404 \\
\hline & The quality of the end product is the responsibility of manufacturers. & 71.0 & 91.9 & $0.030^{*}$ \\
\hline & $\begin{array}{l}\text { Employees from the production site can enter into the Laboratory } \\
\text { Quality Control Department. }\end{array}$ & 33.3 & 18.9 & 0.196 \\
\hline & $\begin{array}{l}\text { It is important to conduct heavy metal test on the final products } \\
\text { manufactured. }\end{array}$ & 75.9 & 84.4 & 0.523 \\
\hline
\end{tabular}

aPercentage of employees that agreed with the statement $\left(\mathrm{n}=39\right.$ employees), ${ }^{\mathrm{b}}$ Statistical significance accepted at $\mathrm{p}<0.05$. 
The overall percentage of employees' awareness on GMP before and after attending the training was shown in fig. 2. Based on the data presented all sections showed an increase in percentage after undergoing training. Majority of the employees that undergone the GMP training showed better understanding of the GMP practice.

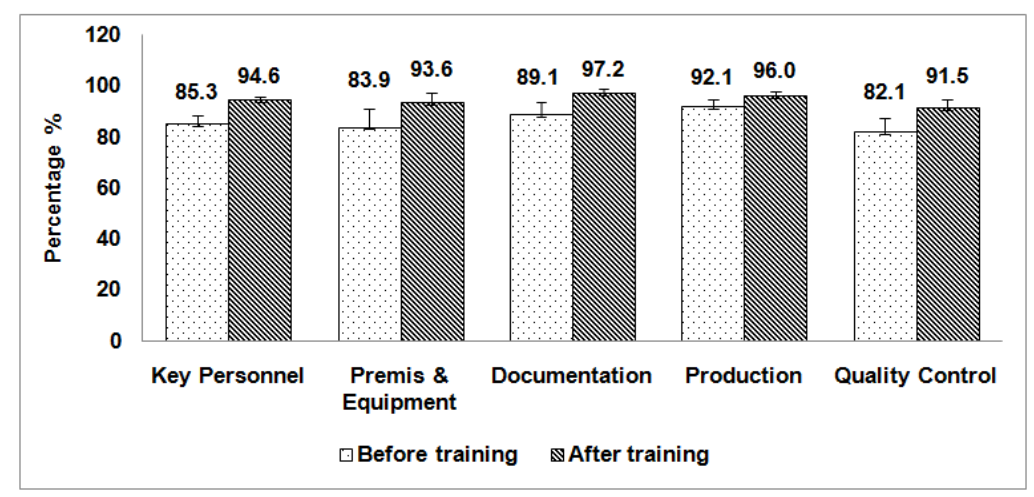

Fig. 2: Overall percentage of employees' awareness on GMP before and after attending the training

\section{DISCUSSION}

Good manufacturing practices have been implemented in Malaysia by all sectors including traditional medicine companies for licensing. GMP for licensing is a primary requirement for companies operation. SME's companies often struggle to adhere with GMP's guideline due to globalisation, shortening product lifecycle, and increasing labour cost that has created a challenging environment to manufacturers to excel. Knowing that collaboration between UiTM with a selected SME's company was initiated to help increase the employees' knowledge on GMP. This was parallel with the Malaysian government aspiration which targeted for Malaysian traditional products to meet world standard and marketed globally.

During the study, a skilful and experienced trainer was appointed to help the graduate intern to design a GMP training course for the employees. The training materials were prepared according to the standard GMP guidelines. An effective GMP training should be able to reduce the employees' performance gap and human errors as well as increase their performance [16]. It is the manufacturers' responsibility to have a well-designed, effectively delivered, regularly evaluated and frequently updated training programs [17]. Besides, an effective training should express employees' responsibility in every task they perform with utmost care and commitment [18]. During the training, the ventilation and documentation system of the company were improved. A centralized ventilation system ensures hygienic working environment because maintenance work are done above the ceiling and outside of the building. A good ventilation system is a must to create a hygienic and comfortable working environment [19]. Meanwhile, a good SOP is a part of good documentation system as clearly written procedures can prevent errors resulting from spoken communication [20].

The employees' knowledge on GMP is evaluated before and after GMP training. The data of few selected questions showed a significant increase after training. From the data presented, it is known that the employees' knowledge on GMP was successfully increased after the training. It is said that preventing errors is more effective than finding rejects because detecting all rejects seems to be impossible [21].

The first section of key personnel emphasized on good, safe and hygienic working habits according to the standard procedure. The personal hygienic practice is crucial for products' safety. Compliance with the hygienic working habits, the premise design and equipment also contributed to major impact for the company as confusion in the layout will cost them the huge cost for maintenance, cleanliness and also renovation [22]. A good premise should considers the location, premise design, floor, walls, ceiling, windows, water supply, drainage, toilets, changing rooms, ventilation system, lighting and storage [23].
Among all, the second most important section is the documentation. A systematic documentation should include the company's regulation, company policy documents and standard operating procedure [20]. It is a reliable quality standard to avoid crosscontamination, mix-ups (false labelling) and unintentional substitution of raw materials [24] (for example, substitute of used herbs with a toxic species). The production and quality control sections highlighted on the materials and finished products handling. The final product is definitely the manufacturer's responsibility. Caution in products manufacturing such as heavy metal test could avoid products contamination with heavy metal as reported by Ang and Lee (2006) [25]. Saleh and Nelson (2006) reported that managerial capability, lack of finance, and access to technology have become part of the challenges faced by the Malaysian SMEs [26]. Despite these challenges, all are encouraged to focus on the solution.

Hence, universities and educational colleges [27] along with the support from National Pharmaceutical Regulatory Agency (NPRA) could offer short-term programmes on GMP for SMEs.

\section{CONCLUSION}

This research has met its objectives and successfully able to increase awareness of employees after a series of scheduled and standardised GMP training. The five main sections were intensively taught throughout the training. Increase in percentage indicates that employees have a better understanding on GMP after training. The authors suggest at least one training per year to strengthen, refresh and update employees' knowledge on GMP. This was suggested based on several observations and experiences at the manufacturing areas.

\section{Limitation of study}

This study is limited to only one company with a small group of respondent which may affect the generalization of its result. However, this study has showed some insights on the importance of GMP training as it would affect the quality of the products. Hence, it is expected that in future researchers could use this as a basic reference to expanding the study on GMP training regularly with a larger sample size as well as involving several companies in traditional medicines industry or other related SMEs.

\section{ACKNOWLEDGEMENT}

The authors involved in the research would like to thank Faculty of Pharmacy University Teknologi MARA, Puncak Alam Campus and Che Mah Sons Sdn Bhd for the support and cooperation in the completion of the study. This study was financially supported by Knowledge Transfer Grant Scheme (43802013001), Ministry of Higher Education, the government of Malaysia. 


\section{AUTHORS CONTRIBUTIONS}

\section{Gurmeet Kaur Surindar Singh}

The author is a senior lecturer at the Faculty of Pharmacy, UiTM. She contributed in writing the research paper and data interpreting.

\section{Ku Aizuddin Ku Azman}

The author contributed in data interpretation and analysis.

\section{Muhamad Anuri Abdul Hadi}

He mainly involved in handling and developing GMP training program for production personnel in one of the established traditional product manufacturing in Malaysia.

\section{Zailintun Jaafar}

The author is a quality assurance manager in one of an established traditional product manufacturing company in Malaysia. Her experience in traditional product GMP and quality control has provided critical and relevant input in this manuscript.

\section{Meor Mohd Redzuan Meor Mohd Affandi}

The author is a senior lecturer at the Department of Pharmaceutics, Faculty of Pharmacy, UITM. He was involved in the concept designing, interpretation and writing of the present study. His research interests include drug delivery, nanotechnology, industrial pharmacy and physical pharmacy. He headed pharmaceutical production department for $13 \mathrm{y}$ prior to his employment as a senior lecturer has enabled him to provide critical idea and input in cGMP related matters.

\section{CONFLICT OF INTERESTS}

The authors declared none

\section{REFERENCES}

1. Willig SH. Good manufacturing practices for pharmaceuticals: a plan for total quality control from manufacturer to consumer. $5^{\text {th }}$ ed. New York: Marcel Dekker Inc; 2001.

2. Nasaruddin RR, Mel M, Fuad F, Jaswir I, Hamid HA. The importance of a Standardized Islamic manufacturing (IMP) for food and pharmaceutical productions. Proceedings of the 2 nd International Conference on Professional Ethics and Education in Engineering 2011. International Islamic University Malaysia, Kuala Lumpur; 2011. p. 401-8.

3. World Health Organization. Conference on traditional medicine strategy 2014-2023. Geneva; 2014. p. 15.

4. Holst L, Wright D, Haavik S, Nordeng H. The use and the user of herbal remedies during pregnancy. J Alternative Complementary Med 2009;15:787-92.

5. Hassan F, Shaaban J. Use of traditional/complementary medicine (T/CM) among adult patients attending family medicine clinic at hospital Universiti Sains Malaysia. Intern Med J 2005;12:133-8.

6. Kumadoh D, Ofori-Kwakye K. Dosage forms of herbal medicinal products and their stability considerations-an overview. J Crit Rev 2017;4:1-8.

7. Meor Mohd Affandi MMR, Julianto T, Majeed ABA. Enhanced oral bioavailability of astaxanthin with droplet size reduction. Food Sci Technol Res 2012;18:549-54.

8. Rupeshkumar M, Kavitha K, Haldar PK. Role of herbal plants in the diabetes mellitus therapy: an overview. Int J Appl Pharm 2014;6:1-3.
9. Normah MA. SMEs: Building blocks for economic growth Proceedings of the National Statistics Conference, National Statistics Departments, Kuala Lumpur; 2006. p. 1-13.

10. Jamal JA. Malay traditional medicine: an overview of scientific and technological progress. Tech Monitor; 2006. Available from: http://www.techmonitor.net/tm/images/2/21/06nov_ dec_sf3.pdf. [Last accessed on 15 Nov 2016]

11. Roziah A, Farhan R. Proceedings of the Hala tuju industri herba di bawah NKEA. Persidangan Industri Herba 2015 Memperkasa Jalinan Industri Herba ke Arah Transformasi Ekonomi. Asiah. eds. Institute Penyelidikan Perhutanan Malaysia, Kepong, Selangor, Malaysia; 2015. p. 6-12.

12. St Pierre J, Raymond L. Short-term effects of benchmarking on the manufacturing practices and performance of SMEs. Intern J Prod Perform Manage 2004;53:681-99.

13. World Health Organization. Guidelines on Manufacturing Practices (GMP) for herbal medicines, Geneva; 2007.

14. Paul KC, Hamzah A, Samah BA, Ismail IA, D’Silva JL. Technology implementation barrier of rural Malay herbal entrepreneurship in Malaysia. J Appl Sci 2014;14:72-6.

15. Paul KC, Hamzah A, Samah BA, Ismail IA, D'Silva JL. Development of rural herbal entrepreneurship in Malaysia. Int J Business Manage 2013;8:95-100.

16. Sultana M. Impact of training in the pharmaceutical industry: An assessment on Square Pharmaceuticals Limited, Bangladesh. Intern J Sci Res 2013;2:576-87.

17. Bringslimark V. If training is so easy, why isn't everyone in compliance? Biopharm Intern 2004;17:46-53.

18. Pai RD, Kamath KK, Subramanyam EVS, Shabaraya AR. Personnel training for pharmaceutical industry. Int J Pharm Qual Assurance 2016;7:55-61.

19. Schmidt RH, Erickson DJ. Sanitary design and construction of food processing and handling facilities. FSHN 07-03, Department of Food Science and Human Nutrition, Florida Cooperative Extension Service, IFAS, University of Florida; 2014. p. 1-8. Available from: http://edis.ifas.ufl.edu/ pdffiles/FS/FS12000.pdf. [Last accessed on 15 Dec 2016]

20. Patel KT, Chotai NP. Documentation and records: Harmonized GMP requirements. J Young Pharm 2011;3:138-50.

21. Shadle PJ. Overview of GMPs. BioPharm Intern; 2004. Available from: http://www.biopharminternational.com/overviewgmps. [Last accessed on 03 Oct 2016]

22. Jali MB, Ghani MA, Norazmir MN. The confusion of design and facilities in good manufacturing practice requirements among industries in Malaysia. Proceedings of the EnvironmentBehaviour Proceedings Journal; 2016. p. 156-67.

23. Malaysian Standard MS 1514:2009. Good Manufacturing Practice (GMP) for food. Department of Standard Malaysia (First revision); 2009. Available from: http://www. mift.org.my/home/articles-of-interest/60-ms-1514-malaysianstandard-on-gmp.html. [Last accessed on 05 Jan 2017]

24. Hussin A. Adverse effects of herbs and drug-herbal interactions. Malay J Pharm 2001;1:39-44.

25. Ang HH, Lee KL. Contamination of mercury in tongkat Ali hitam herbal preparations. Food Chem Toxicol 2006;44:1245-50.

26. Saleh AL, Nelson ON. SME development in Malaysia: domestic and global challenges; 2006. Available from: http://researchpubs@uow.edu.au. [Last accessed on 21 Nov 2015]

27. Kristensen HG. Teaching of industrial pharmacists: How to teach? Am J Pharm Ed 1997;61:197-9. 